\title{
ExCEL: A Unique Approach to Providing Experiential Learning Opportunities
}

\author{
Kelton Friedrich \\ McMaster University \\ friedrke@mcmaster.ca
}

\begin{abstract}
McMaster University's proposed Engineering Centre for Experiential Learning (ExCEL) is a novel example of providing a deep student learning experience outside of the traditional academic experience, and one in which experiential learning opportunities are intended to drive the development of additional learning opportunities. The ExCEL Initiative has students engaged in goal setting and fundraising, and actively involved in the design, construction and management of an engineering student centre building that will support future experiential learning opportunities for students. This integrates a diverse range of engineering pedagogical topics including open ended design, multi-disciplinary collaboration, sustainability, work-integrated learning, industry-academic collaboration, project-based learning and professional development. This learning opportunity will be analyzed on how it was leveraged and integrated to address this host of pedagogical topics through a real world project. Detailing this unique example will allow the rich learning aspects of it to be implemented by other educators in other engineering education institutions.
\end{abstract}

Keywords: Experiential learning, student engagement, novel learning experience, professional development, project-based learning, open ended design, multidisciplinary collaboration, sustainability education.

\section{INTRODUCTION}

The need for the Engineering Centre for Experiential Learning (ExCEL) at McMaster University was identified when other engineering student design centers were constructed across Canada. McMaster's Faculty of Engineering saw that these other engineering student design centers provided a rich learning environment: with the ExCEL building, McMaster Engineering hopes to expand upon and enhance learning opportunities offered by these template design centers. The institutional setting at McMaster has allowed for a very novel approach to all aspects of the design, construction and operation phases of the ExCEL Building. McMaster's embrace of a learner centered and collaborative culture has enabled a student inclusive approach to the design and operation of the ExCEL building: a process unique to the ExCEL building. This deeper level of student engagement was facilitated by ensuring alignment with McMaster's vision for student learning by actually offering opportunities for student participation in what is normally a process left to "the experts".

The outcome has been a continuous opportunity for students to engage in solving real world challenges related to a building that will provide students with ongoing experiential learning opportunities once built.

As of the submission of this paper, the ExCEL building is just moved into the formal design stage and is retaining the first professional building design consultants to work on the building's design. These design consultants will build on more than three years of initial student design work.

As is stated in ExCEL's name, supporting student experiential learning is the primary goal of ExCEL. During the preliminary discussions about ExCEL, it was decided to have a subsidiary goal of designing ExCEL to be a "Living Lab of Sustainability" to reflect McMaster Engineering's commitment to sustainability. This was originally perceived as providing passive means with which students could learn about the building's features that contributed to helping it target a Net-Zero Energy Building. These have remained the primary objectives of the ExCEL building but have evolved to a wider interpretation than first conceived. For example, initially ExCEL was conceived to better support already existing experiential learning opportunities within the Faculty of Engineering, such as engineering related extracurricular clubs and teams, with the Solar Car team being an example. However, this has broadened and ExCEL is now being designed to be flexible and easily modified to meet the needs of experiential learning opportunities that currently do not exist. Such future opportunities could include faculty-run programs that directly provide experiential learning and new engineering related extracurricular clubs that haven't yet been formed.

Another example of the evolution of the goals of ExCEL is that after students provided input on how to 
have ExCEL function as a "Living Lab of Sustainability", it was suggested that rather than students passively being taught about the building features, the building features should be connected with the curriculum in a more active manner. The new motto that was developed with student consultation, "A Building for Students, Designed and Managed by Students" embodies the experiential goal of the building by having students deeply involved with solving real world day to day challenges.

\section{EXPERIENTIAL LEARNING OPPORTUNITIES USED}

A variety of methods to engage student in the ExCEL project were used. This variety of current student learning opportunities catered to different student development aspects, while still helping ExCEL become more successful at supporting future student experiential learning opportunities.

\subsection{ExCEL's Functional Program Development}

The impetus for starting discussions about ExCEL was driven by:

-Existing extra-curricular teams and clubs asking for space resources

-Faculty staff and students comparing McMaster to other schools that had student design centers

-Dean of Engineering valuing the benefit of extracurricular experiential learning

The development and refinement of the functional program has been driven by the work of students acting in various capacities, where they are supported and mentored by faculty professors and staff, including:

-Final year capstone teams that surveyed students and assessed requirements of space

-Final year capstone teams that performed literature reviews on existing "Green Buildings", preformed design analysis and developed recommendations on how to design a "Living Lab of Sustainability"

\subsection{Funding}

Funding for the ExCEL building proved a challenge since it did not fit the traditional model of infrastructure funding. Although this lack of funding was a large challenge, it forced the development of creative solutions. One solution was that by constructing a small building solely for supporting experiential learning there was the potential for all necessary funding to come from alumni and faculty supporter donations. In addition, since there would be no government educational funding, we could follow the model of the existing campus student centre, and have engineering students contribute to the cost of the building through a student contribution, provided the students agreed to do so through a referendum.

To enhance the success of getting the necessary funding through these venues, students were deeply involved right from the start:

-Students were asked to be key leaders in raising awareness among other students of the student referendum

-Students helped set up a "Student Awareness Team" primarily composed of members of the new engineering leadership program SELECT, with mentorship by faculty staff

-The "Student Awareness Team" developed social media communications, posters, organized presentations to give at start of engineering classes, delivered information sessions, and helped with website development

-Students assisted in the development of multiple studio quality informational videos, which were shown on the website and used during class presentations

-Summer students assisted in fundraising activities through outreach to alumni, by organizing alumni awareness events

-Summer students assisted with completing funding request applications from various funding agencies for specific features of the ExCEL building

-Students are acting as student ambassadors to potential donors

\subsection{Design}

The design of the ExCEL building offered the students the deepest learning experience for developing their technical engineering skills. For this reason, it has been the area where there has been the most student involvement as well as the most student interest. Student involvement in developing the Functional Program often led into the preliminary technical design, where students were using technical analysis for sizing building systems to meet various user and building code requirements. Examples of how students had an impact on the design include:

-Final year capstone team evaluated potential building sites on campus and draft conceptual design

-Final year capstone teams did technical design of building energy systems in which they investigated how to reach the targeted Net-Zero Energy goal. These teams worked on energy systems design: their efforts resulted in 2 technical papers for the industry association ASHRAE [1][2].

-Summer students hired to continue capstone teams' work on sizing and integrating systems to meet goals 
-Summer students developed projects for capstone teams for the following year such as life cycle analysis projects for comparing construction material selection, as well as projects on technology specific design integration into the building systems

-The ExCEL Sustainable Building Design Club and the ExCEL User Group Committee were formed, which were mentored by faculty staff. This allowed students outside of final year capstone teams to get directly involved with design

-Sustainable Building Design Club student members made suggestions on technical topics not addressed by prior students, such as water efficiency and rain water capture

-User Group Committee participation allowed all students to get involved with functional program development. Students suggested ways of optimizing utilization of space through shared extra-curricular club and team offices, and suggesting online group meeting room booking policies

-Summer students were hired again in the following year for the positions of Sustainable Building Design Analyst and Experiential Learning Space Deign Analyst

-Summer students were catalysts for expanding ExCEL goals to include new experiential learning opportunities: they suggested designing the building to accommodate new clubs and teams to start in future, proposed developing new extra-curricular learning programs to fill identified gaps, suggested starting a task force on experimental learning, and proposed including space in building to support all phases of the Kolb Experiential Learning Cycle, particularly reflection [3]

-Summer students helped develop additional final year capstone projects such as new ways of providing secure access within the building, counting occupants for a building energy balance and inclusion of donated building envelop products

-Summer students have been hired in this, the 3rd year of design, to analyze how to use building features as experiential teaching tools. One student per department has been hired to look at how proposed features in the building could be used as teaching tools for a particular curriculum course, via assignment questions or in class examples or undergraduate labs. This goes beyond the traditional educational experience that is provided by highly sustainable buildings. The traditional educational experience normally consists of a website or kiosk that interested students can browse through, and labeling of features within the building that are often pointed out during tours. In comparison, integrating design and real-time performance data from the building into the curriculum on a wide scale will ensure greater utilization of the learning potential of the building's features than the traditional approach

-Plans going forward: Part of evaluation criteria for professional building design consultants is how many engineering intern students they planned to hire as an incentive for them to do so

-Plans going forward: Design consultants are expected to mentor and provide information to relevant capstone projects

\subsection{Project Governance}

Given that current students are partially funding the building, and given that ExCEL is "A Building for Students, Designed and Managed by Students", a way to include students in the prioritizing and budgeting of the design and construction of the ExCEL building was required. A building steering committee was set up, composed of faculty professors and staff as well as students:

-Student representatives have voting rights on the steering committee for making financial decisions for the building

-Students have been asked to do research and provide recommendations to steering committee on prioritizing user space allocation and resource needs

\subsection{Management and Operation}

Once the building is constructed and being used, day to day management of the facility will be required. This provides another opportunity for student engagement, and it is proposed that student representatives will sit on a building operations committee:

-Students will be involved with developing policies for safe, fair and effective use of the space by individual students and student clubs and teams

-A Stewardship Agreement was suggested by students as a tool to deal with allocating space to extra-curricular clubs and teams competing for limited space and resources. Student representatives would be part of evaluation team assessing extra-curricular club's and team's submissions

-Students proposed that in future, a program be set up for incentivizing older students to act as mentors for younger students on how to use tools, equipment and software effectively in the ExCEL building

\section{RESULTS}

The pedagogical results of the various learning opportunities provided to students working on the ExCEL project were not measured through assessing the student's 
competencies before and after the learning experience. Thus, there is no direct evidence to quantify the impact of these learning experiences' on improving student competencies. However, indirect assessments of the benefits of these learning experiences could be made by comparing them to studies that did quantify the learning outcomes of learning experiences that were similar. Additionally, feedback from students and faculty professors suggests that the learning experiences associated with ExCEL were very effective in developing student competencies.

The final year capstone projects that worked on ExCEL provided the traditional project-based learning and open ended design experience to assist professional development that capstone projects provide. The focus on ExCEL resulted in more sustainability focused projects, as well as increased student participation since they wanted to see their work successfully integrated into the finished building. To date, just over 90 students have been intimately involved in the various design aspects of ExCEL through final year capstone project teams spanning most departments within Engineering.

The summer student positions provided the rich learning experience that comes with work-integrated learning. Although these are probably some of the strongest learning experiences students can have, it is unfortunate that the faculty cannot provide more due to resource limitations. However, with a well-targeted focus, these summer student positions provided a great benefit for assessing the predesign of a building for a relatively low cost to the faculty. The unique learning opportunities that the ExCEL building will provide would not be as numerous without the efforts of the summer students.

The Student Awareness Team, Sustainable Building Design Club and the User Group Committee offered novel learning experiences for students, particularly given their multi-disciplinary composition. Although extra-curricular clubs and teams already exist, the ones developed for the ExCEL building provided new and different learning experience. What was particularly interesting is that since the ExCEL building will be supporting existing extracurricular clubs and teams, it required the existing clubs and teams to do a thorough evaluation of themselves, so that they could represent their interests effectively when meeting to discuss space and resource requirements.

Through all these opportunities for student engagement, students demonstrated a strong commitment to developing effective solutions to the problems presented. This could be partially attributed to the deep sense of student ownership over the project, as well as students wanting to leave a strong legacy for future students. Student participation and engagement have helped this project move forward, and at the same time, have enabled students to enrich their learning experiences, while tackling real-world, open-ended, engineering problems.

The students that were most passionate about the project and took the strongest sense of student ownership, also tended to be those most involved in the project governance around goal setting and financial decision making. When the focus is on improving the student experience, students are very critical of using funding for things not going to benefit students in the future. These students helped make the tough choices on what features would be in scope and out of scope for the fixed budget, as faculty professors and staff were challenged to clearly justify how any of the features they were proposing would enhance the student experience.

One of the most unique aspects of the ExCEL project is how it uses current student experiential learning opportunities to develop experiential learning opportunities for future students. Rather than the traditional approach of just faculty professors and staff working to develop new learning opportunities for future students, the approach used for ExCEL provides another layer of learning opportunities, expanding the benefit to students. Not only does this approach provide more deep hands-on learning experiences for students, but it enhances the effectiveness of the future student learning experiences by embedding the perspectives that current students bring to our understanding of how students learn.

\section{CONCLUSION}

From the various experiential learning opportunities that were provided to students by the ExCEL building project, a number of conclusions can be drawn.

Students working on developing the functional program and technical design of building are provided with rich experiential learning experiences. The project offers many curricular and extra-curricular opportunities that can be scaled to meet student time availability, utilize current competencies and develop new skills, while working on a real campus building project. In these various venues students can develop novel and effective solutions and recommendations that help advance the project while at the same time meeting their educational requirements.

Students are an effective use of resources, particularly when the task is, developing new learning opportunities for future students. The student perspective has been very beneficial throughout the project life cycle, starting from conceptual functional program development, through fundraising, technical design and including financial budgeting. However, students need good mentors and support to be effective, and cannot be left fully independent. Additionally, students will have a deeper learning experience and will develop more effective 
solutions if they feel a sense of ownership over the project. Getting students to fund the project is probably not practical in most cases. However, getting students to recognize they are leaving a legacy for future students if they come up with effective solutions can help instill a sense of ownership.

From McMaster's Faculty of Engineering experience, it would be recommended that other Engineering educational institutions consider using various venues to engage students more deeply on campus project design as a way to provide a strong experiential learning opportunity for students. This does not have to be limited to just buildings, but could include program element development and laboratory experiment design.

\section{Acknowledgements}

I would like to acknowledge Dr. David Wilkinson for his initial vision of ExCEL, Dr. Arthur Heidebrecht for his continued support to develop ExCEL, the faculty professors and staff that have guided this project, the alumni that have financially supported ExCEL, and certainly not least, the many students that have made ExCEL what it is.

\section{References}

[1] Caldwell, T., K. Friedrich, B. Gregus, R. Verschuere, J. Anderson, A. Murenbeeld, K. Arfaei, M. Boroumand, D.S. Wilkinson, J.S. Cotton. "Targeting a net-zero energy student center-Part 1: Thermal and electrical load minimization," ASHRAE Transactions, 118(2):27683. 2012.

[2] Friedrich, K., T. Caldwell, T., B. Gregus, R. Verschuere, J. Anderson, A. Murenbeeld, K. Arfaei, M. Boroumand, D.S. Wilkinson, J.S. Cotton. "Targeting a net-zero energy student center-Part 2: Systems to meet building loads," ASHRAE Transactions, 118(2):269-76. 2012.

[3] Kolb, A., and D. Kolb, The Kolb Learning Style Inventory Version 3.1. HayGroup, 2005. 